OPEN ACCESS

Edited by:

Francesco Cicone,

Lausanne University Hospital (CHUV),

Switzerland

Reviewed by:

Yidong Yang,

University of Miami, United States

Eric D. Laywell,

Florida State University College of

Medicine, United States

${ }^{*}$ Correspondence:

Sam Donche

sam.donche@ugent.be

Specialty section: This article was submitted to

Nuclear Medicine,

a section of the journal

Frontiers in Medicine

Received: 25 October 2018

Accepted: 10 January 2019

Published: 29 January 2019

Citation:

Donche S, Verhoeven J, Descamps B, Bolcaen J, Deblaere K, Boterberg T,

Van den Broecke $C$, Vanhove $C$ and Goethals I (2019) The Path Toward

PET-Guided Radiation Therapy for Glioblastoma in Laboratory Animals: A Mini Review. Front. Med. 6:5. doi: 10.3389/fmed.2019.00005

\section{The Path Toward PET-Guided Radiation Therapy for Glioblastoma in Laboratory Animals: A Mini Review}

\author{
Sam Donche ${ }^{1 *}$, Jeroen Verhoeven ${ }^{2}$, Benedicte Descamps ${ }^{3}$, Julie Bolcaen ${ }^{1}$, \\ Karel Deblaere ${ }^{1}$, Tom Boterberg ${ }^{4}$, Caroline Van den Broecke ${ }^{5}$, Christian Vanhove ${ }^{3}$ and \\ Ingeborg Goethals ${ }^{1}$
}

${ }^{1}$ Department of Radiology and Nuclear Medicine, Ghent University, Ghent, Belgium, ${ }^{2}$ Department of Pharmaceutical Analysis, Ghent University, Ghent, Belgium, ${ }^{3}$ Department of Electronics and Information Systems, Ghent University, Ghent, Belgium, ${ }^{4}$ Department of Radiation Oncology and Experimental Cancer Research, Ghent University, Ghent, Belgium,

${ }^{5}$ Department of Pathology, Ghent University, Ghent, Belgium

Glioblastoma is the most aggressive and malignant primary brain tumor in adults. Despite the current state-of-the-art treatment, which consists of maximal surgical resection followed by radiation therapy, concomitant, and adjuvant chemotherapy, progression remains rapid due to aggressive tumor characteristics. Several new therapeutic targets have been investigated using chemotherapeutics and targeted molecular drugs, however, the intrinsic resistance to induced cell death of brain cells impede the effectiveness of systemic therapies. Also, the unique immune environment of the central nervous system imposes challenges for immune-based therapeutics. Therefore, it is important to consider other approaches to treat these tumors. There is a well-known dose-response relationship for glioblastoma with increased survival with increasing doses, but this effect seems to cap around 60 Gy, due to increased toxicity to the normal brain. Currently, radiation treatment planning of glioblastoma patients relies on $\mathrm{CT}$ and $\mathrm{MRI}$ that does not visualize the heterogeneous nature of the tumor, and consequently, a homogenous dose is delivered to the entire tumor. Metabolic imaging, such as positron-emission tomography, allows to visualize the heterogeneous tumor environment. Using these metabolic imaging techniques, an approach called dose painting can be used to deliver a higher dose to the tumor regions with high malignancy and/or radiation resistance. Preclinical studies are required for evaluating the benefits of novel radiation treatment strategies, such as PET-based dose painting. The aim of this review is to give a brief overview of promising PET tracers that can be evaluated in laboratory animals to bridge the gap between PET-based dose painting in glioblastoma patients.

Keywords: PET, radiation therapy, laboratory animals, dose painting, glioblastoma, tumor heterogeneity

\section{INTRODUCTION}

Brain tumors are relatively rare when compared with breast, lung, prostate, and colorectal cancer, however, malignant brain tumors are among the most feared types of cancer. Besides poor prognosis, these tumors have a direct impact on quality of life and cognitive function (1). Tumors originating from glial cells, the so-called gliomas (2), can be classified into low-grade gliomas 
(LGG, WHO grade I-II) and high-grade gliomas (HGG, WHO III-IV). Glioblastoma (GB, WHO IV) is the most aggressive and malignant primary brain tumor. Usually, GB is a solid tumor that can be characterized by infiltrative boundaries, heterogeneous composition, and hemorrhage (3). In contrast to WHO I to III gliomas, GB exhibits microvascular proliferation and necrosis as a defining feature (4). GB is also characterized by disruption of the blood-brain barrier, which is responsible for leakage of gadolinium-based agents in contrast-enhanced magnetic resonance imaging (MRI) (5). The infiltrative growth often delays early diagnosis until symptoms from mass effect arise. It also renders a complete surgical resection nearly impossible without causing significant neurological injury. Hence, residual glioma cells at the tumor margins frequently lead to tumor recurrence (6).

Despite the discovery of several novel therapeutic targets for chemo- and immunotherapy (7), none have proven to be effective due to the anatomically and immunologically nature of the brain $(8,9)$. Consequently, the treatment for GB patients has stagnated since the introduction of the Stupp protocol in 2005, which consists of maximal surgical resection followed by combined external beam radiation therapy (RT) and concomitant temozolomide, followed by adjuvant temozolomide for newly diagnosed GB patients with a good performance status (10). Therefore, alternative treatment approaches are necessary. There is a well-known dose-response relationship for glioblastoma with increased survival with increasing doses, but this effect seems to cap around $60 \mathrm{~Gy}$, due to increased toxicity to the normal brain (11). As a result, additional information from metabolic imaging techniques, such as positron-emission tomography (PET), for target volume definition during radiotherapy planning is a reasonable option. These techniques enable the visualization of biological tumor features in vivo and may facilitate customization of dose prescription.

Since only a limited amount of information can be obtained through clinical trials and because it has been hypothesized that a better understanding can be obtained from downscaling to small animals $(12,13)$, preclinical studies using precision image-guided radiation research platforms (14) are relevant for investigating current unresolved challenges in radiation oncology toward personalized medicine and novel treatment strategies, such as dose painting (15). In addition, certain experimental setups (e.g., autoradiography) cannot be performed in the clinic. The purpose of most preclinical RT studies is to translate discovery to human trials and preclinical RT studies should be designed to flow over into a Phase I clinical trial (15). On the other hand, preclinical research can be carried out in parallel with or subsequent to clinical trials to gain de novo understanding about trial conclusions (16). However, preclinical data must be interpreted accurately and limitation of these preclinical setups have to be considered (15). The aim of this review is to give a brief overview of promising PET tracers that can be evaluated in laboratory animals to bridge the gap between PET-based dose painting in glioblastoma patients.

\section{RADIATION THERAPY PLANNING}

\section{Biological Target Volume}

Neuroimaging is of major importance for RT planning. Shortly after its introduction, computed tomography (CT)-based conformal RT planning was incorporated into the standard of care for cancer patients. Whereas, MRI provides superior tumor visualization, CT remains fundamental for dosimetry, and imaging dose-limiting organs (17). On CT and conventional MRI, two main tumor volumes for RT planning are delineated: the gross tumor volume (GTV), identifying the position and extent of the macroscopic gross tumor, and the clinical target volume (CTV) that contains the GTV plus a margin for subclinical disease spread, which cannot be fully imaged, and is crucial for maximization of the radiation dose to the tumor. Subsequently, another margin is incorporated to account for setup and delivery uncertainties to obtain the planning target volume (PTV) $(18,19)$. Currently, GTV for GB is determined by $\mathrm{T}_{1}$-weighted contrast-enhanced $\mathrm{MRI}$ and $\mathrm{T}_{2}$ /fluid-attenuated inversion recovery (FLAIR) sequences. An isotropic expansion of these margins results in the CTV (20).

In 2000, an additional concept was introduced, namely the biological target volume (BTV) that can be derived from functional or molecular imaging techniques, such as PET. For example, the tumor burden or hypoxic tumor region obtained through magnetic resonance spectroscopy (MRS) and $\left[{ }^{18} \mathrm{~F}\right] \mathrm{FMISO}$ (see further), respectively, are important to consider when planning RT (21). It was suggested by Navarria et al. that BTV may lead to a more accurate delineation of the CTV as tumor recurrences are often situated in this region (22). It was also shown that the volume of BTV is correlated with the overall survival in GB patients (23). With the increased availability of metabolic information and appreciation for tumor heterogeneity (see further), radiation oncologists started to consider an evolution from the traditional concept of a uniform dose distribution toward a non-uniform dose distribution (24).

\section{Dose Painting}

In the majority of HGG, intratumor heterogeneity is established through the diverging genetic drift of tumor subclones. These subclones respond to the therapy to a varying degree and are often spatially segregated (25). Fast dividing tumor clones can be associated with proliferation corresponding with highly malignant tumor regions. Hypoxic tumor regions can be associated with reduced oxygenation. This oxygen deficiency is a primum movens for the development of radiation resistance or radiation insensitivity, which in turn is the basis for tumor recurrence (25). This additional information on biological tumor variation can be integrated into radiotherapy planning in order to facilitate heterogeneous radiation therapy (26). In 2000, Ling et al. introduced the term "dose painting" in a review paper on multidimensional radiotherapy (21). The concept of dose painting is to "paint" an increased radiation dose on tumor volumes with more radiation resistance and/or malignancy. Dose painting can be accomplished in two ways: dose painting by contours (DPBC) and dose painting by numbers (DPBN), 


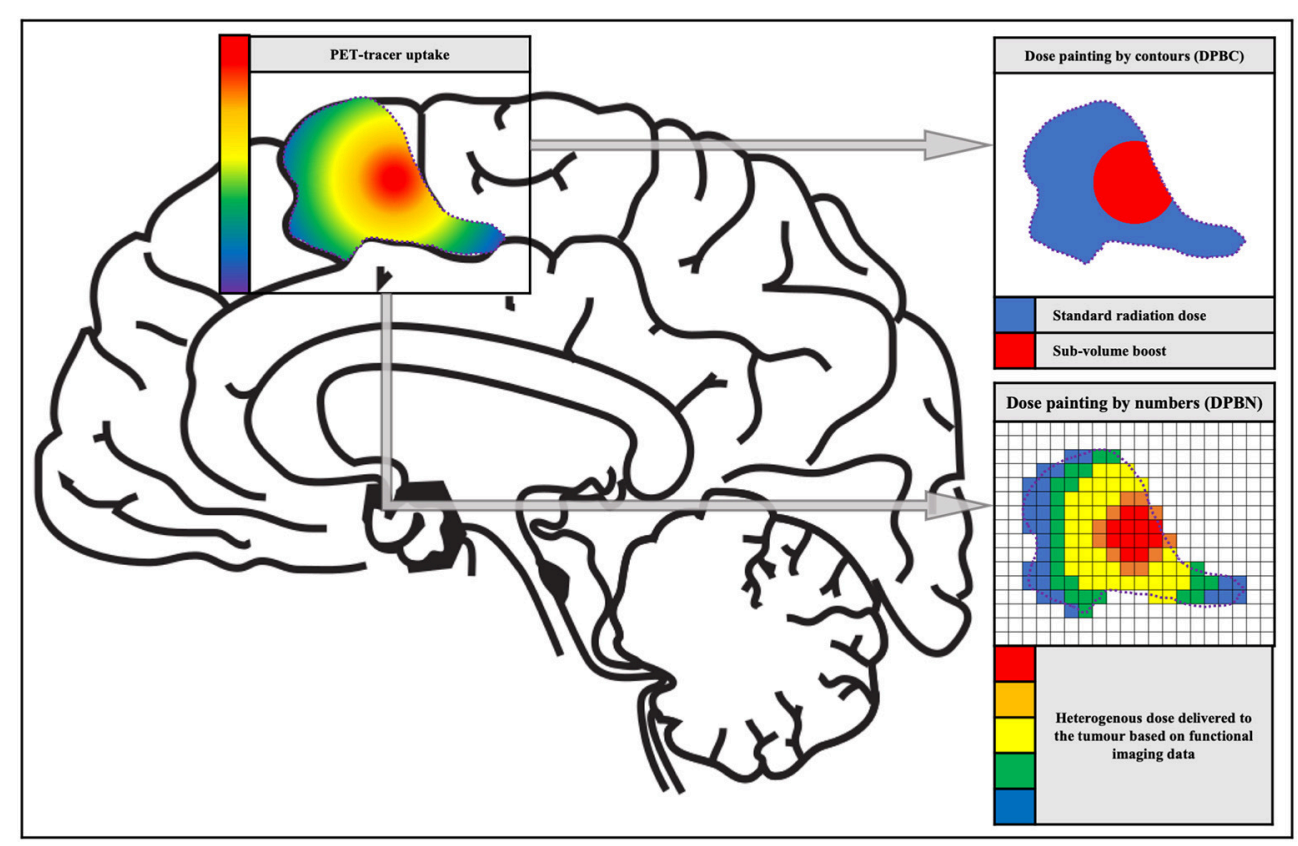

FIGURE 1 | The concept of dose painting. Schematic representation of the two dose painting methods: dose painting by contours (DPBC) and dose painting by numbers (DPBN). The image and color bar on the left show the PET tracer uptake. The images and color scales on the right display a discrete fictive dose distribution for radiation therapy.

whereby a dose is given to a set of nested sub-volumes or at voxel level, respectively (25) (see Figure 1).

When DPBC (also called sub-volume boosting) is utilized, a sub-volume within the GTV is treated with a higher (uniform) dose compared with the rest of the PTV to obtain an improved treatment outcome $(27,28)$. A drawback of discrete volumes is that they are binary, which means voxels are either inside or outside the volume. However, in biological reality, one can observe gradients in hypoxic tissue, cellular phenotypes and malignancy, and by differentiating only one sub-volume a substantial amount of information is lost. This discrepancy has led to the development of dose painting by numbers (25).

In DPBN, the dose for each voxel is calculated incorporating the intensity of the corresponding voxel in e.g., a PET image. This method often uses a lower and upper boundary, to make sure that enough dose is delivered to every part of the tumor while protecting the organs at risk. The most basic method is a linear interpolation between the minimum and maximum dose, proportional to the minimum and maximum intensity within the target volume (29). However, there is some skepticism about the quality assurance of DPBN, which might have an increased risk of radiation-induced secondary cancers (25).

The most optimal dose painting approach still has to be demonstrated through (pre)clinical research. For instance, a prospective phase II study evaluated the integrated boost intensity-modulated dose escalation concept using $\left[{ }^{18} \mathrm{~F}\right] \mathrm{FET}$ to obtain a better local tumor control. However, the results showed that dose escalation did not lead to a survival benefit (30).

\section{PET IMAGING IN GLIOBLASTOMA}

As mentioned above, RT planning is critically dependent on neuroimaging. MRI and CT represent the two most important and commonly used imaging modalities. The former is the method of choice for assessment of tumor volume and location while the latter is mandatory for RT planning. However, despite the remarkable soft tissue contrast of (conventional) MRI, it offers a limited grasp on malignancy grade, infiltration into the surrounding normal tissue, tumor heterogeneity, and differentiation between (radio)necrosis and recurrent tumor (20). For instance, tumor cells can be found at a $\mathrm{cm}$ range from the contrast enhancing tumor part on MRI $(31,32)$. Furthermore, pseudo-progression and pseudo-response (image alterations due to therapy rather than tumor evolution) complicate response assessment in glioma using conventional MRI $(33,34)$.

Molecular imaging techniques, such as PET, provide additional information on tumor biology. PET may have an impact on tumor delineation for RT planning because increased tracer uptake after surgery can often be found outside the contrast-enhancing region or the $\mathrm{T}_{2}$ /FLAIR tumor volume on MRI (35). Thus, by incorporating PET imaging into RT planning an improved local tumor control and a reduced exposure of healthy tissue can be obtained (5). In addition, biological changes may precede anatomical changes after the start of therapy. This information can serve different purposes, such as more accurate diagnosis, biopsy guidance, and adaptive radiation treatment $(36,37)$. In the past decades, a variety of tracers have been developed as imaging agents for different metabolic pathways 
of neuro-oncologic cells that might be promising for PET-based radiation treatment.

\section{$\left[{ }^{18}\right.$ F]Fluorodeoxyglucose PET}

The most (pre)clinically used PET tracer in oncology is 2-deoxy-2- $\left[{ }^{18} \mathrm{~F}\right]$ fluoro-D-glucose $\left(\left[{ }^{18} \mathrm{~F}\right] \mathrm{FDG}\right)$ because it has a high potential to detect tumors in the body based on the increased energy (glucose) requirements of malignant tumors $(5,38)$. However, localization and delineation of (primary) brain tumors is often difficult due to the high background glucose metabolism of normal brain parenchyma. Only coregistration of $\left[{ }^{18} \mathrm{~F}\right]$ FDG PET with MRI allows accurate assessment of glucose metabolism in specific areas of the tumor $(5,36,39)$. Despite this phenomenon, it is worth mentioning that it has been demonstrated that delayed $\left[{ }^{18} \mathrm{~F}\right] \mathrm{FDG}$ imaging $(3-8 \mathrm{~h}$ after tracer injection) improves the distinction between tumor and normal gray matter because the washout of glucose is higher in normal brain tissue than in tumor tissue $(39,40)$. Although $\left[{ }^{18} \mathrm{~F}\right] \mathrm{FDG}$ PET-guided radiation therapy is routinely used to treat other cancer types, e.g., head-and-neck cancer (41), PET guidance using amino acid tracer seems to be more suitable for these procedures $(42,43)$.

\section{Amino-Acid PET}

Due to their relatively low uptake in normal brain parenchyma (5) and low variability in delineation amongst operators (44), radiolabelled amino acids, and amino acid analogs are the most commonly used PET tracers for neuro-oncological imaging (39, 45).

In the early 1980s, L- (methyl- $\left.\left[{ }^{11} \mathrm{C}\right]\right)$-methionine $\left(\left[{ }^{11} \mathrm{C}\right] \mathrm{MET}\right)$ was introduced as PET tracer for imaging brain tumors $(46,47)$. Over several decades, $\left[{ }^{11} \mathrm{C}\right]$ MET PET has demonstrated its value in the initial diagnosis and image-guided biopsy $(42,48,49)$, the detection of tumor recurrence $(50,51)$, tumor prognosis $(52)$, and RT planning $(5,53-55)$.

Although most PET studies of gliomas are performed with $\left[{ }^{11} \mathrm{C}\right] \mathrm{MET}$, the short half-life of the radioisotope $\left[{ }^{11} \mathrm{C}\right](\sim 20 \mathrm{~min})$ is a major drawback, which necessitates the presence of a cyclotron nearby the clinical facility. Therefore, amino acid (analog) PET tracers labeled with radioisotopes with a longer half-life were developed, e.g., O- $\left(2-\left[{ }^{18} \mathrm{~F}\right]\right.$ fluoroethyl $)-\mathrm{L}$-tyrosine $\left(\left[{ }^{18} \mathrm{~F}\right] \mathrm{FET}\right)$ and 3,4-dihydroxy-6- $\left[{ }^{18} \mathrm{~F}\right]$ fluoro-L-phenylalanine $\left(\left[{ }^{18} \mathrm{~F}\right] \mathrm{FDOPA}\right)$ labeled with $\left[{ }^{18} \mathrm{~F}\right]$ (half-life $\sim 110 \mathrm{~min}$ ). Previous studies have shown that both $\left[{ }^{18} \mathrm{~F}\right] \mathrm{FET}$ and $\left[{ }^{18} \mathrm{~F}\right] \mathrm{FDOPA}$ provide analogous (diagnostic) information compared to $\left[{ }^{11} \mathrm{C}\right] \mathrm{MET}$ PET in glioma patients $(44,56)$.

Currently, $\left[{ }^{18} \mathrm{~F}\right] \mathrm{FET}$ is the preferred clinical tracer for brain tumors and its diagnostic potential is well-documented (36, $57,58)$. The vast majority of HGG show increased $\left[{ }^{18} \mathrm{~F}\right] \mathrm{FET}$ uptake. However, the absence of $\left[{ }^{18} \mathrm{~F}\right] \mathrm{FET}$ uptake does not exclude the diagnosis of glioma, since a considerable number of LGG are $\left[{ }^{18} \mathrm{~F}\right] \mathrm{FET}$ negative (59). The superior delineation of $\left[{ }^{18} \mathrm{~F}\right] \mathrm{FET}$ PET for glioma patients in biopsy and RT guidance in comparison with MRI was repeatedly shown $(45,60,61)$. $\left[{ }^{18} \mathrm{~F}\right]$ FET PET has also been used for the definition of an integrated boost to residual tumor after initial surgery (30) and recurrent tumor (62).

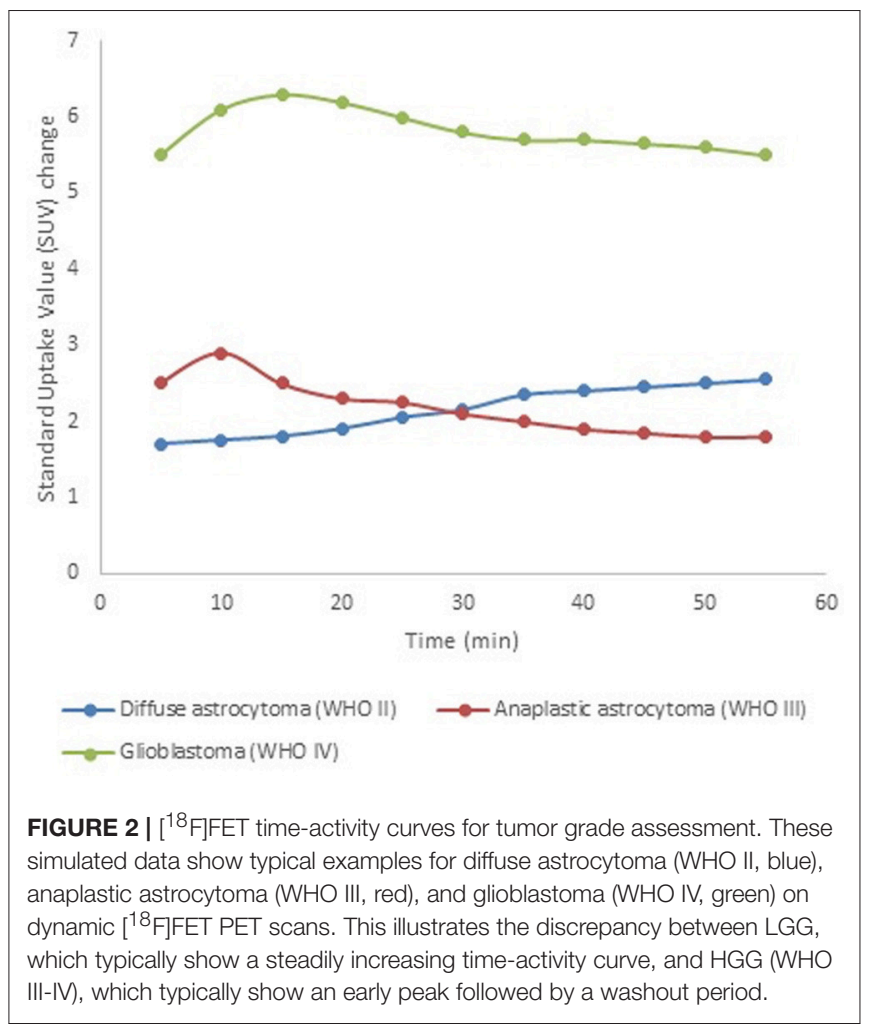

Furthermore, in addition to static images, dynamic $\left[{ }^{18} \mathrm{~F}\right] \mathrm{FET}$ PET data can be acquired, providing significantly more information on both temporal and spatial tracer uptake. The time-to-peak and the shape of the $\left[{ }^{18} \mathrm{~F}\right] \mathrm{FET}$ time-activity curve have been shown valuable for patient care (63). For example, tumor grading accuracy can be substantially improved through the assessment of dynamic $\left[{ }^{18} \mathrm{~F}\right] \mathrm{FET}$ PET data, which typically show steadily increasing time-activity curves in WHO grade II gliomas, as opposed to an early activity peak $(\sim 10-20 \mathrm{~min}$ after injection), followed by a decrease of $\left[{ }^{18} \mathrm{~F}\right] \mathrm{FET}$ uptake in WHO grade III/IV gliomas (see Figure 2) $(64,65)$. These data have proven to be important for therapy response assessment (66), in differentiating progressive or recurrent glioma from treatmentrelated non-neoplastic changes (67), and in the assessment of prognosis (68-70).

\section{Hypoxia PET}

Tumor oxygenation has an essential role when considering resistance to radiation therapy. In 1955, the negative effect of tumor hypoxia on tumor outcome was demonstrated (71). Inadequate oxygen supply results in changes in metabolism and cellular proliferation (72), which results for example in a required radiation dose up to three times higher than the dose for well-oxygenated tissues $(5,73)$. Detection of this phenomenon in tumors has a high clinical relevance because tumor aggressiveness, metastatic spread, failure to achieve local tumor control, increased rate of recurrence, and ultimately poor outcome are all associated to hypoxia $(5,72,74,75)$.

The first developed hypoxia PET tracer was $\left[{ }^{18} \mathrm{~F}\right]$ fluoromisonidazole $\quad\left(\left[{ }^{18} \mathrm{~F}\right] \mathrm{FMISO}\right) . \quad\left[{ }^{18} \mathrm{~F}\right] \mathrm{FMISO}$ can 
passively diffuse through the membrane and binds covalently to intracellular proteins under hypoxic conditions, resulting in tracer accumulation within hypoxic cells $(5,36,38,73,76)$. With regard to therapy response assessment, the volume and the intensity of hypoxia signal on $\left[{ }^{18} \mathrm{~F}\right] \mathrm{FMISO}$ PET in GB before radiation therapy was strongly correlated with poor progression and survival $(39,77)$.

The slow uptake of $\left[{ }^{18} \mathrm{~F}\right]$ FMISO in target tissue and slow clearance of unbound $\left[{ }^{18} \mathrm{~F}\right] \mathrm{FMISO}$ from non-hypoxic areas has led to the development of $\left[{ }^{18} \mathrm{~F}\right]$ fluoroazomycin-arabinoside $\left(\left[{ }^{18} \mathrm{~F}\right] \mathrm{FAZA}\right)$ with improved pharmacokinetics $(74,78)$. In the majority of gliomas, a clear distinction between hypoxic tumor tissue and normal parenchyma could be observed $2 \mathrm{~h}$ after intravenous injection of $\left[{ }^{18} \mathrm{~F}\right] \mathrm{FAZA}$ (79). Nevertheless, further research is needed before the abovementioned hypoxia tracers can be incorporated in PET-guided RT for glioma patients.

\section{SMALL ANIMAL PET-GUIDED RADIATION THERAPY}

For many decades, laboratory animal radiation research was mostly performed using fairly crude experimental setups (14). The delivery of radiation in small animals was achieved using fixed radiation sources (80-82) or linear accelerators producing megavoltage X-rays (83-85) and applying only a single radiation field $(82-84,86)$. This approach often results in full/partial body irradiation or in the best case at a precision of a few $\mathrm{mm}$, while sub-millimeter precision is required for small animals (14). Furthermore, simple single-beam techniques were commonly used without the ability to target a specific tumor volume, hampering response assessment due to high doses delivered to healthy brain tissue $(14,82,84,85,87)$. These techniques significantly differ from the advanced 3D imageguided radiotherapy techniques using conformal arcs in clinical practice (13).

To enable more accurate (conformal) irradiation in laboratory animal research, precision image-guided small animal radiation research platforms were developed. These platforms typically integrate a $\mathrm{kV} \mathrm{X}$-ray source that is used for imaging and radiation treatment, a computer-controlled stage for animal positioning, a rotational gantry assembly to allow radiation delivery from various angles, and a collimating system to shape the radiation beam. The Small Animal Radiation Research Platform (SARRP, XStrahl ${ }^{\circledR}$, Surrey, UK) (13), developed at Johns Hopkins University School of Medicine, uses a $225 \mathrm{kV}$ $\mathrm{X}$-ray tube that is mounted on a motorized arm that rotates around an animal stage that can displace in three orthogonal directions and rotate around the vertical axis. A "fixed" on-board flat panel detector allows for cone beam computer tomography by rotating the animal stage around its vertical axis. Nozzleshaped or a motorized variable collimator provides circular and rectangular radiation fields with different dimensions. The $\mathrm{X}$ RAD 225Cx (Precision X-Ray Inc., North Branford, US) (88) from Princess Margeret Hospital uses the same X-ray tube as the SARRP, however, the animal stage is fixed, and X-ray tube and detector panel rotate around the stage. Different circular and rectangular beam sizes can be used during irradiation. At the University of Texas Southwestern, a fixed high energy Xray tube of $320 \mathrm{kV}$ is combined with a fixed imaging panel. The principle of the animal stage is similar to the one of the SARRP, except the fact that it rotates around its horizontal axis instead of its vertical axis $(89,90)$. A group at Stanford University modified the eXplore RS120 microCT scanner to use it as a small animal radiation platform with an excellent spatial imaging resolution. Pseudo-circular radiation fields are produced by an iris-shaped collimator to deliver beams at $120 \mathrm{kV}$. The system has its own treatment planning system and produces small penumbras for small fields, nevertheless heating problems, and a low efficiency to deliver high doses prevented the system from being commercialized (91). Finally, the image-guided Small Animal Arc Radiation Treatment system (iSMAART) from the University of Miami (92-94) consists of an X-ray source, a flat panel detector, a charge-coupled detector (CCD), and an animal stage capable of rotating and $x-y-z$ translation. All the components remain stationary except the rotating animal stage, which allows to acquire CT, tomographic bioluminescent, and tomographic fluorescent images for guided treatment delivery. The development and commercialization of small animal image-guided radiotherapy devices has decreased the technological gap with clinical RT. The number of preclinical trials using these devices for precision small animal RT has been steadily increasing over the past years. Now, researchers are capable to conduct preclinical investigations in a manner that more closely resembles the clinical scenario and these devices have the potential to address current challenges regarding PET-based dose painting strategies $(15,95)$.

However, while dose calculations in the clinic are done by inverse treatment planning, whereby one starts from a desired dose distribution to calculate the beams via an (iterative) algorithm, small animal irradiators often function with forward planning. In forward planning, the radiotherapy planner selects the number and angle of beams. The computer then calculates the dose distribution. The plan is optimized by manual iteration, which is labor intensive (96). From 2009 and onwards, research efforts have been made to implement inverse planning on these research platforms as well (97-99). To further increase conformity with the clinical situation, a motorized variable rectangular collimator was developed as a preclinical counterpart of the multi-leaf collimator. In 2014, Cho et al. presented a 2D dose painting method using this variable collimator (100).

Recently, the same group implemented a 3D inverse treatment planning procedure on a micro-irradiator and defined a minimum dose for the target volume and a maximum dose for the OAR (101). These techniques have mostly been evaluated in silica and application in laboratory animals still needs to be investigated.

Similar to the clinical situation, treatment planning on these radiation research platforms is based on CT (102). However, (preclinical) CT is hampered by insufficient soft-tissue contrast, which makes brain tumor localization very challenging. To improve target selection, CT on these preclinical research platforms is increasingly being combined with functional 
imaging modalities, such as PET and bioluminescent imaging (38).

The implementation of PET for RT planning is still under investigation in the clinic (103-105) and preclinical research might provide new insights for combining PET with RT. Evidently, PET-based RT planning requires correct registration with the planning CT to obtain accurate treatment planning. This process can be simplified by using a multi-modality bed to move the animal from the PET to the micro-irradiator and, ideally, a (semi-) automatic registration algorithm should be used to minimize intra- and inter-observer variability. The major weaknesses of PET imaging for RT planning are the relatively long acquisition times, the high cost of a PET scanner and limited spatial resolution (1-2 mm range). Moreover, integrating a PET device into a preclinical radiation research platform is far from trivial. These limitations might be related to the success of optical molecular imaging techniques to guide RT, such as bioluminescence and fluorescence imaging. Optical imaging is free of ionizing radiation, is a relatively inexpensive imaging technique with short acquisition times and the compact footprint enables it to be integrated into a micro-irradiator. Several groups have demonstrated the feasibility to integrate optical imaging into a micro-irradiator $(93,94,106-108)$. Related to image guidance, bioluminescent imaging provides excellent signal-tobackground ratios due to the negligible background signal, while various fluorescent probes are available for tumor-specific target imaging. However, optical imaging suffers from absorption and scattering of visible light by tissue, limiting the spatial resolution and the accuracy to localize a target. Fluorescence imaging is also hampered by auto-fluorescence, resulting in a background artifact, and it should be noted that bioluminescent imaging is difficult to translate to the clinic because it requires genetic manipulations of tumor cells for in vivo applications.

Related to PET-guided RT, only a few promising studies have been carried out. In 2011, $\left[{ }^{18} \mathrm{~F}\right]$ FET PET guidance has been used in boron neutron capture therapy, an alternative radiation treatment approach, in F98-tumor bearing rats (109). In 2015, the use of BTV in a preclinical setup has been positively evaluated by Trani et al. in rat rhabdomyosarcomas (110). Recently, our neuro-oncology research group incorporated PET-based subvolume boosting in the preclinical workflow for RT planning for

\section{REFERENCES}

1. Omuro en DeAngelis LM. Glioblastoma and other malignant gliomas: a clinical review. J Am Med Assoc. (2013) 310:1842-9. doi: 10.1001/jama.2013.280319

2. Louis DN, Perry A, Reifenberger G, von Deimling A, Figarella-Branger D, Cavenee WK, et al. The 2016 World Health Organization classification of tumors of the central nervous system: a summary. Acta Neuropathol. (2016) 131:803-20. doi: 10.1007/s00401-016-1545-1

3. Louis N, Ohgaki H, Wiestler OD, Cavenee WK, Ellison DW, FigarellaBranger D, et al. WHO Classification of Tumours of the Central Nervous System. Lyon: International Agency for Research on Cancer (IARC) (2016).

4. Liu S, Wang Y, Xu K, Wang Z, Fan X, Zhang C, et al. Relationship between necrotic patterns in glioblastoma and patient survival: fractal dimension both $\left[{ }^{18} \mathrm{~F}\right] \mathrm{FET}$ and $\left[{ }^{18} \mathrm{~F}\right] \mathrm{FAZA}(111)$ and this methodology was applied to investigate treatment outcome in a rat model of GB [unpublished data].

\section{CONCLUSION}

Despite research efforts, the treatment of GB patients has stagnated since the introduction of the Stupp protocol. Therefore, novel therapeutic approaches should be investigated for this cancer with a poor prognosis. Routine diagnosis and treatment planning of GB patients is still heavily dependent on contrast-enhanced MRI. Literature has shown the assets of various PET tracers in the different steps of patient care: detection, grading, differentiating tumor recurrence from radionecrosis, prognosis, and therapy response assessment. PET also has the potential to improve tumor delineation for RT due to its capabilities to visualize radiation resistance and/or malignant tumor tissue. The feasibility of PET-based radiation therapy has been clinically investigated for different tracers. It is our opinion that PET should be considered for RT planning of GB because of valuable biological information. Preclinical models have a supporting function toward developing clinical applications, e.g., examination of novel dose painting strategies and radiobiological hypotheses or correlations to histopathology. Also, further development of the preclinical models is still necessary to reach the same degree of complexity and accuracy as their clinical counterpart.

\section{AUTHOR CONTRIBUTIONS}

IG and CV designed and developed the concept of the manuscript. SD wrote the manuscript. IG, CV, JV, BD, JB, $\mathrm{TB}, \mathrm{CVdB}$, and $\mathrm{KD}$ supervised and edited the manuscript. SD prepared Figures 1, 2. All authors discussed and commented on the manuscript at all stages.

\section{ACKNOWLEDGMENTS}

We would like to thank Stichting Luka Hemelaere for supporting our research. and lacunarity analyses using magnetic resonance imaging. Sci Rep. (2017) 7:8302. doi: 10.1038/s41598-017-08862-6

5. Lopci, Franzese C, Grimaldi M, Zucali PA, Navarria P, Simonelli M, et al. Imaging biomarkers in primary brain tumours. Eur J Nuclear Med Mol Imaging (2015) 42:597-612. doi: 10.1007/s00259-014-2971-8

6. Huse JT Holland EC. Targeting brain cancer: advances in the molecular pathology of malignant glioma and medulloblastoma. Nat Rev Cancer (2010) 10:319-31. doi: 10.1038/nrc2818

7. Wadajkar S, Dancy JG, Hersh DS, Anastasiadis P, Tran NL, Woodworth GF, et al. Tumor-targeted nanotherapeutics: overcoming treatment barriers for glioblastoma. Wiley Interdiscip Rev. (2017) 9:e1439. doi: 10.1002/wnan.1439

8. Lim M, Xia Y, Bettegowda C, Weller M. Current state of immunotherapy for glioblastoma. Nat Rev Clin Oncol. (2018) 15:422-42. doi: 10.1038/s41571-018-0003-5 
9. McGranahan T, Li G, Nagpal S. History and current state of immunotherapy in glioma and brain metastasis. Ther Adv Med Oncol. (2017) 9:347-68. doi: $10.1177 / 1758834017693750$

10. Stupp R, Mason WP, van den Bent MJ, Weller M, Fisher B, Taphoorn MJ, et al. Radiotherapy plus concomitant and adjuvant temozolomide for glioblastoma. N Engl J Med. (2005) 352:987-96. doi: 10.1056/NEJMoa043330

11. Grosu A-L, Weber W, Feldmann HJ, Wuttke B, Bartenstein P, Gross MW, et al. First experience with I-123-alpha-methyl-tyrosine spect in the 3-D radiation treatment planning of brain gliomas. Int J Radiat Oncol Biol Phys. (2000) 47:517-26. doi: 10.1016/S0360-3016(00)00423-5

12. van Hoof SJ, Granton PV, Verhaegen F. Development and validation of a treatment planning system for small animal radiotherapy: SmARTPlan. Radiother Oncol. (2013) 109:361-6. doi: 10.1016/j.radonc.2013. 10.003

13. Wong J, Armour E, Kazanzides P, Iordachita I, Tryggestad E, Deng H, et al. High-resolution, small animal radiation research platform with Xray tomographic guidance capabilities. Int J Radiat Oncol Biol Phys. (2008) 71:1591-9. doi: 10.1016/j.ijrobp.2008.04.025

14. Verhaegen F, Granton P, Tryggestad E. Small animal radiotherapy research platforms. Phys Med Biol. (2011) 56:R55-83. doi: 10.1088/0031-9155/56/12/R01

15. Butterworth KT, Prise KM, Verhaegen F. Small animal image-guided radiotherapy: status, considerations and potential for translational impact. Br J Radiol. (2014) 88:20140634. doi: 10.1259/bjr.20140634

16. Abate-Shen, Pandolfi PP. Effective utilization and appropriate selection of genetically engineered mouse models for translational integration of mouse and human trials. Cold Spring Harbor Protoc. (2013) 2013:pdb-top078774. doi: $10.1101 /$ pdb.top078774

17. MacManus M, Nestle U, Rosenzweig KE, Carrio I, Messa C, Belohlavek $\mathrm{O}$, et al. Use of PET and PET/CT for radiation therapy planning: IAEA expert report 2006-2007. Radiother Oncol. (2009) 91:85-94. doi: 10.1016/j.radonc.2008.11.008

18. Jansen EPM, Dewit LGH, van Herk M, Bartelink H. Target volumes in radiotherapy for high-grade malignant glioma of the brain. Radiother Oncol. (2000) 56:151-6. doi: 10.1016/S0167-8140(00)00216-4

19. Higgins J, Bezjak A, Hope A, Panzarella T, Li W, Cho JBC, et al. Effect of image-guidance frequency on geometric accuracy and setup margins in radiotherapy for locally advanced lung cancer. Int J Radiat Oncol Biol Phys. (2011) 80:1330-7. doi: 10.1016/j.ijrobp.2010.04.006

20. Frosina G. Positron emission tomography of high-grade gliomas. J Neuro Oncol. (2016) 127:415-25. doi: 10.1007/s11060-016-2077-1

21. Ling C, Humm J, Larson S, Amols H, Fuks Z, Leibel S, et al. Towards multidimensional radiotherapy (MD-CRT): biological imaging and biological conformality. Int J Radiat Oncol Biol Phys. (2000) 47:551-560. doi: 10.1016/S0360-3016(00)00467-3

22. Navarria P, Reggiori G, Pessina F, Ascolese AM, Tomatis S, Mancosu P, et al. Investigation on the role of integrated PET/MRI for target volume definition and radiotherapy planning in patients with high grade glioma. Radiother Oncol. (2014) 112:425-9. doi: 10.1016/j.radonc.2014.09.004

23. Suchorska B, Jansen NL, Linn J, Kretzschmar H, Eigenbrod S, Simon $\mathrm{M}$, et al. Biological tumor volume in 18FET-PET before radiochemotherapy correlates with survival in GBM. Neurology (2015) 84:710-9. doi: 10.1212/WNL.0000000000001262

24. Devic S. Towards biological target volumes definition for radiotherapy treatment planning: Quo Vadis PET/CT? J Nuclear Med Radiat Ther. (2013) 4:1-10. doi: 10.4172/2155-9619.1000158

25. Bentzen SM. Theragnostic imaging for radiation oncology: dose-painting by numbers. Lancet Oncol. (2005) 6:112-7. doi: 10.1016/S1470-2045(05)01737-7

26. Bainbridge $H$, Salem A, Tijssen RHN, Dubec $M$, Wetscherek A, Van Es C, et al. Magnetic resonance imaging in precision radiation therapy for lung cancer. Transl Lung Cancer Res. (2017) 6:689-707. doi: $10.21037 /$ tlcr.2017.09.02

27. Thorwarth D, Geets X, Paiusco M. Physical radiotherapy treatment planning based on functional PET/CT Data. Radiother Oncol. (2010) 96:317-24. doi: 10.1016/j.radonc.2010.07.012

28. Chao KSC, Bosch WR, Mutic S, Lewis JS, Dehdashti F, Mintun MA, et al. A novel approach to overcome hypoxic tumor resistance: $\mathrm{Cu}$-ATSM-guided intensity-modulated radiation therapy. Int J Radiat Oncol Biol Phys. (2001) 49:1171-82. doi: 10.1016/S0360-3016(00)01433-4

29. Alber M, Paulsen F, Eschmann SM, Machulla HJ. On biologically conformal boost dose optimization. Phys Med Biol. (2003) 48:31-5. doi: 10.1088/0031-9155/48/2/404

30. Piroth MD, Pinkawa M, Holy R, Klotz J, Schaar S, Stoffels G, et al. Integrated boost IMRT with FET-PET-adapted local dose escalation in glioblastomas. Strahlentherapie und Onkol. (2012) 188:334-9. doi: 10.1007/s00066-011-0060-5

31. Eidel O, Burth S, Neumann J-O, Kieslich PJ, Sahm F, Jungk C, et al. Tumor infiltration in enhancing and non-enhancing parts of glioblastoma: a correlation with histopathology. PLoS ONE (2017) 12:e0169292. doi: 10.1371/journal.pone.0169292

32. Grosu A-L, Geldmann HJ, Dick S, Dzewas B, Nieder C, Gumprecht H, et al. Implications of IMT-SPECT for postoperative radiotherapy planning in patients with gliomas. Int J Radiat Oncol Biol Phys. (2002) 54:842-54. doi: 10.1016/S0360-3016(02)02984-X

33. Chang JH, Kim C-Y, Choi BS, Kim YJ, Kim JS, Kim IA Pseudoprogression and pseudoresponse in the management of high-grade glioma: optimal decision timing according to the neurooncology Working Group. J Korean Neurosurg Soc. (2014) 55:5-11. doi: 10.3340/jkns.2014.55.1.5

34. Wen PY, Macdonald DR, Reardon DA, Cloughesy TF, Sorensen AG, Galanis $\mathrm{E}$, et al. Updated response assessment criteria for high-grade gliomas: response assessment in neuro-oncology working group. J Clin Oncol. (2011) 28:1963-72. doi: 10.1200/JCO.2009.26.3541

35. Grosu A-L, Weber WA, Riedel E, Jeremic B, Nieder C, Franz M, et al. L-(Methyl-11C) methionine positron emission tomography for target delineation in resected high-grade gliomas before radiotherapy. Int J Radiat Oncol Biol Phys. (2005) 63:64-74. doi: 10.1016/j.ijrobp.2005.01.045

36. Demetriades K, Almeida AC, Bhangoo RS, Barrington SF. Applications of positron emission tomography in neuro-oncology: a clinical approach. Surgeon (2014) 12:148-57. doi: 10.1016/j.surge.2013.12.001

37. Dhermain G, Hau P, Lanfermann $H$, Jocobs $A H$, van den Bent MJ. Advanced MRI and PET imaging for assessment of treatment response in patients with gliomas. Lancet Neurol. (2010) 9:906-20. doi: 10.1016/S1474-4422(10)70181-2

38. James ML, Gambhir SS. A molecular imaging primer: modalities, imaging agents, and applications. Physiol Rev. (2012) 92:897-965. doi: 10.1152/physrev.00049.2010

39. Bolcaen J, Acou M, Descamps B, Kersemans K, Deblaere K, Vanhove C, et al. Chapter 10: PET for Therapy Response Assessment in Glioblastoma. In: De Vleeschouwer S, editor. Glioblastoma. Brisbane, QLD:Codon Publications (2017). p. 175-96. doi: 10.15586/codon.glioblastoma.2017.ch10

40. Mertens K, Acou M, Van Hauwe J, De Ruyck I, Van den Broecke C, Kalala J-P, et al. Validation of 18F-FDG PET at conventional and delayed intervals for the discrimination of high-grade from low-grade gliomas: a stereotactic PET and MRI study. Clin Nuclear Med. (2013) 38:495-500. doi: 10.1097/RLU.0b013e318292a753

41. Duprez, De Neve W, De Gersem W, Coghe M, Madani I. Adaptive dose painting by numbers for head-and-neck cancer. Int J Radiat Oncol Biol Phys. (2011) 80:1045-55. doi: 10.1016/j.ijrobp.2010.03.028

42. Pirotte B, Goldman S, Massager N, David P, Wikler D, Lipszyc M, et al. Combined use of $18 \mathrm{~F}$-fluorodeoxyglucose and $11 \mathrm{C}$-methionine in 45 positron emission tomography-guided stereotactic brain biopsies. $J$ Neurosurg. (2004) 101:476-83. doi: 10.3171/jns.2004.101.3.0476

43. Lammering G, De Ruysscher D, van Baardwijk A, Baumert BG, Borger J, Lutgens LP, et al. The use of FDG-PET to target tumors by radiotherapy. Strahlenther Onkol. (2010) 186:471-81. doi: 10.1007/s00066-0102150-1

44. Grosu A-L, Astner ST, Riedel E, Nieder C, Wiedenmann N, Heinemann F, et al. An interindividual comparison of O-(2-[18F] Fluoroethyl)-L-Tyrosine (FET)-and L-[Methyl-11C] methionine (MET)-PET in patients with brain gliomas and metastases. Int J Radiat Oncol Biol Phys. (2011) 81:1049-58. doi: 10.1016/j.ijrobp.2010.07.002

45. Galldiks N, Langen K-J. Amino acid pet - an imaging option to identify treatment response, posttherapeutic effects, and tumor recurrence? Front Neurol. (2016) 7:120. doi: 10.3389/fneur.2016.00120 
46. Bergström M, Collins VP, Ehrin E, Ericson K, Greitz T, Halldin C, et al. Discrepancies in brain tumor extent as shown by computed tomography and positron emission tomography using [68Ga]EDTA, [11C]glucose, and [11C]methionine. J Comput Assist Tomogr. (1983) 7:10626. doi: 10.1097/00004728-198312000-00022

47. Ericson K, Lilja A, Bergström M, Collins VP, Eriksson L, Ehrin E, et al. Positron emission tomography with ([11C]methyl)-L-methionine, [11C]Dglucose, and [68Ga]EDTA in supratentorial tumors. J Comput Assist Tomogr. (1985) 6:683-9. doi: 10.1097/00004728-198507010-00005

48. Braun V, Dempf S, Weller R, Reske SN, Schachenmayr W, Richter HP. Cranial neuronavigation with direct integration of $11 \mathrm{C}$ methionine positron emission tomography (PET) data - results of a pilot study in 32 surgical cases. Acta Neurochirurgica (2002) 144:777-82. doi: 10.1007/s00701-002-0942-5

49. Kracht LW, Miletic H, Busch S, Jacobs AH, Voges J, Hoevels M, et al. Delineation of brain tumor extent with [11C]L-methionine positron emission tomography: local comparison with stereotactic histopathology. Clin Cancer Res. (2004) 10:7163-70. doi: 10.1158/1078-0432.CCR-04-0262

50. Coope J, Cízek J, Eggers C, Vollmar S, Heiss W-D, Herholtz K. Evaluation of primary brain tumors using 11C-methionine PET with reference to a normal methionine uptake map. J Nuclear Med. (2007) 48:1971-80. doi: $10.2967 /$ jnumed.107.043240

51. Terakawa Y, Tsuyuguchi N, Iwai Y, Yamanaka K, Higashiyama S, Takami $\mathrm{T}$, et al. Diagnostic accuracy of 11C-methionine PET for differentiation of recurrent brain tumors from radiation necrosis after radiotherapy. J Nuclear Med. (2008) 49:694-9. doi: 10.2967/jnumed.107.048082

52. De Witte O, Goldberg I, Wikler D, Rorive S, Damhaut P, Monclus $\mathrm{M}$, et al. Positron emission tomography with injection of methionine as a prognostic factor in glioma. J Neurosurg. (2001) 95:746-50. doi: 10.3171/jns.2001.95.5.0746

53. Schinkelshoek M, Lopci E, Clerici E, Alongi F, Mancosu P, Rodari M, et al. Impact of 11C-methionine positron emission tomography/computed tomography on radiation therapy planning and prognosis in patients with primary brain tumors. Tumori (2014) 100:636-44. doi: 10.1177/1778.19268

54. Grosu L, Weber WA. PET for radiation treatment planning of brain tumours. Radiother Oncol. (2010) 96:325-7. doi: 10.1016/j.radonc.2010.08.001

55. Matsuo M, Miwa K, Shinoda J, Kako N, Nishibori H, Sakurai K, et al. Target definition by C11-methionine-PET for the radiotherapy of brain metastases. Int J Radiat Oncol Biol Phys. (2009) 74:714-22. doi: 10.1016/j.ijrobp.2008.08.056

56. Becherer A, Karanikas G, Szabó M, Zettinig G, Asenbaum S, Marosi C, et al. Brain tumour imaging with PET: a comparison between [18F]fluorodopa and [11C]methionine. Eur J Nuclear Med Mol Imaging (2003) 30:1561-7. doi: 10.1007/s00259-003-1259-1

57. Langen K-J, Hamacher K, Weckesser M, Floeth F, Stoffels G, Bauer $\mathrm{D}$, et al. O-(2-[18F]fluoroethyl)-l-tyrosine: uptake mechanisms and clinical applications. Nuclear Med. Biol. (2006) 33:287-94. doi: 10.1016/j.nucmedbio.2006.01.002

58. Walter F, Cloughesy T, Walter MA, Lai A, Nghiemphy P, Wagle N, et al. Impact of 3,4-Dihydroxy-6-18F-Fluoro-L-Phenylalanine PET/CT on managing patients with brain tumors: the referring physician's perspective. J Nuclear Med. (2012) 53:393-8. doi: 10.2967/jnumed.111.095711

59. Albert NL, Weller M, Suchorska B, Galldiks N, Soffietti R, Kim $\mathrm{MM}$, et al. Response assessment in neuro-oncology working group and european association for neuro-oncology recommendations for the clinical use of pet imaging in gliomas. Neuro Oncol. (2016) 18:1199-208. doi: 10.1093/neuonc/now058

60. Vander Borght T, Asenbaum S, Bartenstein P, Halldin C, Kapucu Ö, Van Laere $\mathrm{K}$, et al. EANM procedure guidelines for brain tumour imaging using labelled amino acid analogues. Eur J Nuclear Med Mol Imaging (2006) 33:1374-80. doi: 10.1007/s00259-006-0206-3

61. Tanaka Y, Nariai T, Momose T, Aoyagi M, Maehara T, Tomori T, et al. Glioma surgery using a multimodal navigation system with integrated metabolic images. J Neurosurg. (2009) 110:163-72. doi: 10.3171/2008.4.17569

62. Niyazi M, Jansen NL, Rottler M, Ganswindt U, Belka C. Recurrence pattern analysis after re-irradiation with bevacizumab in recurrent malignant glioma patients. Radiat Oncol. (2014) 9:299. doi: 10.1186/s13014-014-0299-y

63. Albert NL, Winkelmann I, Suchorska B, Wenter V, Schmid-Tannwald C, Mille E, et al. Early static 18F-FET-PET scans have a higher accuracy for glioma grading than the standard 20-40 min scans. Eur J Nuclear Med Mol Imaging (2016) 43:1105-14. doi: 10.1007/s00259-015-3276-2

64. Pöpperl G, Kreth FW, Mehrkens JH, Herms J, Seelos K, Koch W, et al. FET PET for the evaluation of untreated gliomas: correlation of FET uptake and uptake kinetics with tumour grading. Eur J Nuclear Med Mol Imaging (2007) 34:1933-42. doi: 10.1007/s00259-007-0534-y

65. Galldiks N, Law I, Pope WB, Arbizu J, Langen K-J. The use of amino acid PET and conventional MRI for monitoring of brain tumor therapy. Neuroimage Clin. (2017) 13:386-94. doi: 10.1016/j.nicl.2016.12.020

66. Galldiks N, Langen K-J, Holy R, Pinkawa M, Stoffels G, Nolte KW, et al. Assessment of treatment response in patients with glioblastoma using O-(218F-Fluoroethyl)-L-Tyrosine PET in Comparison to MRI. J Nuclear Med. (2012) 53:1048-57. doi: 10.2967/jnumed.111.098590

67. Galldiks N, Stoffels G, Filss C, Rapp M, Blau T, Tscherpel C, et al. The use of dynamic O-(2-18F-fluoroethyl)-L-tyrosine PET in the diagnosis of patients with progressive and recurrent glioma. Neuro Oncol. (2015) 17:1293-300. doi: 10.1093/neuonc/nov088

68. Jansen NL, Suchorska B, Wenter V, Schmid-Tannwald C, Todica A, Eigenbrod S, et al. Prognostic significance of dynamic 18F-FET PET in newly diagnosed astrocytic high-grade glioma. J Nuclear Med. (2015) 56:9-15. doi: 10.2967/jnumed.114.144675

69. Jansen L, Suchorska B, Wenter V, Eigenbrod S, Schmid-Tannwald C, Zwergal A, et al. Dynamic 18F-FET PET in newly diagnosed astrocytic lowgrade glioma identifies high-risk patients. J Nuclear Med. (2014) 55:1-6. doi: 10.2967/jnumed.113.122333

70. Piroth D, Pinkawa M, Holy R, Klotz J, Nussen S, Stoffels G, et al. Prognostic value of early [18F]Fluurethyltyrosine positron emission tomography after radiochemotherapy in glioblastoma multiforme. Int J Radiat Oncol Biol Phys. (2011) 80:176-84. doi: 10.1016/j.ijrobp.2010. 01.055

71. Thomlinson RH, Gray LH. The histological structure of some human lung cancers and the possible implications for radiotherapy. Br J Cancer (1955) 9:539-49. doi: 10.1038/bjc.1955.55

72. Rajendran JG, Krohn KA. F-18 fluoromisonidazole for imaging tumor hypoxia: imaging the microenvironment for personalized cancer therapy. Semin Nuclear Med. (2015) 45:151-62. doi: 10.1053/j.semnuclmed.2014.10.006

73. Kawai N, Lin W, Cao W-D, Ogawa D, Miyake K, Haba R, et al. Correlation between 18F-fluoromisonidazole PET and expression of HIF$1 \mathrm{a}$ and VEGF in newly diagnosed and recurrent malignant gliomas. Eur J Nuclear Med Mol Imaging (2014) 41:1870-8. doi: 10.1007/s00259-0142776-9

74. Lopci E, Grassi I, Chiti A, Nanni C, Cicoria G, Toschi L, et al. PET radiopharmaceuticals for imaging of tumour hypoxia: a review of the evidence. Am J Nuclear Med Mol Imaging (2014) 4:365-84.

75. Nordsmark M, Overgaard J. Tumor hypoxia is independent of hemoglobin and prognostic for loco-regional tumor control after primary radiotherapy in advanced head and neck cancer. Acta Oncol. (2004) 43:396-403. doi: $10.1080 / 02841860410026189$

76. Vallabhajosula S. 18F-labeled positron emission tomographic radiopharmaceuticals in oncology: an overview of radiochemistry and mechanisms of tumor localization. Semin Nuclear Med. (2007) 37:400-19. doi: 10.1053/j.semnuclmed.2007.08.004

77. Spence M, Muzi M, Swanson KR, O’Sullivan F, Rockhill JK, Rajendran JG, et al. Regional hypoxia in glioblastoma multiforme quantified with [18F]Fluoromisonidazole positron emissiontomography before radiotherapy: correlation with time to progression and survival. Clin Cancer Res. (2008) 14:2623-30. doi: 10.1158/1078-0432.CCR-07-4995

78. Tran L-B, Bol A, Labar D, Karroum O, Bol V, Jordan B, et al. Potential role of hypoxia imaging using 18F-FAZA PET to guide hypoxiadriven interventions (carbogen breathing or dose escalation) in radiation therapy. Radiother Oncol. (2014) 113:204-9. doi: 10.1016/j.radonc.2014. 09.016

79. Postema EJ, McEwan AJ, Riauka TA, Kumar P, Richmond DA, Abrams $\mathrm{DN}$, et al. Initial results of hypoxia imaging using 1-a-D-(5-deoxy5-[18F]-fluoroarabinofuranosyl)-2-nitroimidazole (18F-FAZA). Eur J Nuclear Med Mol Imaging (2009) 36:1565-73. doi: 10.1007/s00259-0091154-5 
80. Kinsella J, Vielhuber KA, Kunugi KA, Schupp J, Davis TW, Sands H. Preclinical toxicity and efficacy study of a 14-day schedule of oral 5-Iodo2-pyrimidinone-2'-deoxyribose as a prodrug for 5-Iodo-2'-deoxyuridine radiosensitization in U251 human glioblastoma xenografts. Clin Cancer Res. (2000) 6:1468-75

81. Kioi M, Vogel H, Schultz G, Hoffman RM, Harsh GR, Brown MJ. Inhibition of vasculogenesis, but not angiogenesis, prevents the recurrence of glioblastoma after irradiation in mice. J Clin Invest. (2010) 120:694-705. doi: 10.1172/JCI40283

82. Vellimana K, Renard Recinos V, Hwang L, Fowers KD, Li KW, Zhang $\mathrm{Y}$, et al. Combination of paclitaxel thermal gel depot with temozolomide and radiotherapy significantly prolongs survival in an experimental rodent glioma model. J Neuro Oncol. (2013) 111:229-36. doi: 10.1007/s11060-012-1014-1

83. Rousseau J, Barth RF, Fernandez M, Adam J-F, Balosso J, Estève F, et al. Efficacy of intracerebral delivery of cisplatin in combination with photon irradiation for treatment of brain tumors. J Neuro Oncol. (2010) 98:287-95. doi: 10.1007/s11060-009-0074-3

84. Vinchon-Petit S, Jarnet D, Jadaud E, Feuvret L, Garcion E, Menei P. External irradiation models for intracranial 9L glioma studies. J Exp Clin Cancer Res. (2010) 29:142. doi: 10.1186/1756-9966-29-142

85. Yang W, Huo T, Barth RF, Gupta N, Weldon M, Grecula JC, et al. Convection enhanced delivery of carboplatin in combination with radiotherapy for the treatment of brain tumors. J Neuro Oncol. (2011) 101:379-90. doi: $10.1007 / \mathrm{s} 11060-010-0272-\mathrm{z}$

86. Baumann C, Benci JL, Santoiemma PP, Chandrasekaran S, Hollander AB., Kao GD, et al. An integrated method for reproducible and accurate image-guided stereotactic cranial irradiation of brain tumors using the small animal radiation research platform. Transl Oncol. (2012) 5:230-7. doi: $10.1593 /$ tlo. 12136

87. Lee Y, John CL, Park SS, Huang J, Martinez AA, Grills IS, et al. Pulsed versus conventional radiation therapy in combination with temozolomide in a murine orthotopic model of glioblastoma multiforme. Int J Radiat Oncol Biol Phys. (2013) 86:978-85. doi: 10.1016/j.ijrobp.2013.04.034

88. Clarkson R, Lindsay PE, Ansell S, Wilson G, Jelveh S, Hill R P, et al. Characterization of image quality and image-guidance performance of a preclinical microirradiator. Med Phys. (2011) 38:845-56. doi: 10.1118/1.3533947

89. Song KH, Pidikiti R, Stojadinovic S, Speiser M, Seliounine S, Saha D, et al. An $\mathrm{X}$-ray image guidance system for small animal stereotactic irradiation. Phys Med Biol. (2010) 55:7345-62. doi: 10.1088/0031-9155/55/23/011

90. Pidikiti R, Stojadinovic S, Speiser M, Song KH, Hager F, Saha F, et al. Dosimetric characterization of an image-guided stereotactic small animal irradiator. Phys Med Biol. (2011) 56:2585-99. doi: 10.1088/0031-9155/56/8/016

91. Zhou H, Rodriguez M, van den Haak F, Nelson G, Jogani R, Xu $\mathrm{X}$, et al. Development of a micro-computed tomography-based image-guided conformal radiotherapy system for small animals. Int $J$ Radiat Oncol Biol Phys. (2010) 78:297-305. doi: 10.1016/j.ijrobp.2009. 11.008

92. Sha H, Udayakumar TS, Johnson PB, Dogan N, Pollack A, Yang Y. An image guided small animal stereotactic radiotherapy system. Oncotarget (2016) 7:18825-36. doi: 10.18632/oncotarget.7939

93. Shi J, Udayakumar TS, Wang Z, Dogan N, Pollack A, Yang Y. Optical molecular imaging-guided radiation therapy part 1: integrated x-ray and bioluminescence tomography. Med Phys. (2017) 44:4786-94. doi: $10.1002 / \mathrm{mp} .12415$

94. Shi J, Udayakumar TS, Wang Z, Dogan N, Pollack A, Yang Y. Optical molecular imaging-guided radiation therapy part 2: Integrated $\mathrm{X}$-ray and fluorescence molecular tomography. Med Phys. (2017) 44:4795-803. doi: $10.1002 / \mathrm{mp} .12414$

95. Verhaegen F, van Hoof S, Granton PV, Trani D. A review of treatment planning for precision image-guided photon beam preclinical animal radiation studies. $Z$ Med Phys. (2014) 24:323-34. doi: 10.1016/j.zemedi.2014.02.004
96. Nasr A, Habash A. Dosimetric analytic comparison of inverse and forward planned IMRT techniques in the treatment of head and neck cancer. J Egypt Natl Cancer Institute (2014) 26:119-25. doi: 10.1016/j.jnci.2014.03.004

97. Matinfar M, Iyer S, Ford E, Wong J, Kazanzides P. Image guided complex dose delivery for small animal radiotherapy. In: IEEE International Symposium. Boston, MA (2009). p. 1243-6. doi: 10.1109/ISBI.2009.5193287

98. Matinfar M, Iordachita I, Wong J, Kazanzides P. Robotic delivery of complex radiation volumes for small animal research. In: IEEE International Conference. Anchorage, AK (2010). p. 2056-61. doi: 10.1109/ROBOT.2010.5509898

99. Balvert M, van Hoof SJ, Granton PV, Trani D, den Hertog D, Hoffmann $\mathrm{AL}$, et al. A framework for inverse planning of beam-on times for 3D small animal radiotherapy using interactive multi-objective optimisation. Phys Med Biol. (2015) 60:5681-98. doi: 10.1088/0031-9155/60/14/5681

100. Cho NB,Wong J, Kazanzides P. Dose Painting with a Variable Collimator for the Small Animal Radiation Research Platform (SARRP). Boston, MA: MICCAI Workshop on Image-Guided Adaptive Radiation Therapy (IGART) (2014). Available online at: http://hdl.handle.net/10380/3476

101. Cho NB, Wong J, Kazanzides P. Fast inverse planning of beam directions and weights for small animal radiotherapy. IEEE Trans Radiat Plasma Med Sci. (2018) 2:215-22. doi: 10.1109/TRPMS.2018.2805876

102. Baker R. Localization: conventional and CT simulation. Br J Radiol. (2006) 79:36-49. doi: 10.1259/bjr/17748030

103. Chiti A, Kirienko M, Grégoire V. Clinical use of PET-CT data for radiotherapy planning: what are we looking for? Radiother Oncol. (2010) 96:277-9. doi: 10.1016/j.radonc.2010.07.021

104. Grégoire V, Chiti A. PET in radiotherapy planning: particularly exquisite test or pending. Radiother Oncol. (2010) 96:275-6.

105. Soykut D, Ozsahin EM, Guney YY, Arslan SA, Or OD, Altundag MB, et al. The use of PET/CT in radiotherapy planning: contribution of deformable registration. Front Oncol. (2013) 3:33. doi: 10.3389/fonc.2013.00033

106. Yang Y, Wang KK, Eslami S, Iordachita II, Patterson MS. Systematic calibration of an integrated $\mathrm{x}$-ray and optical tomography system for preclinical radiation research. Med Phys. (2015) 42:1710-20. doi: 10.1118/1.4914860

107. Zhang B, Wang KK, Yu J, Eslami S, Iordachita I, Reyes J, et al. Bioluminescence Tomography-Guided Radiation Therapy for Preclinical Research. Int J Radiat Oncol Biol Phys. (2016) 94:1144-53. doi: 10.1016/j.ijrobp.2015.11.039

108. Weersink RA, Ansell S, Wang A, Wilson G, Shah D, Lindsay PE et al. Integration of optical imaging with a small animal irradiator. Med Phys. (2016) 42:102701. doi: 10.1118/1.4894730

109. Menichetti L, Petroni D, Panetta D, Burchielli S, Bortolussi S, Matteucii M, et al. A micro-PET/CT approach using O-(2-[18F]fluoroethyl)-L-tyrosine in an experimental animal model of F98 glioma for BNCT. Appl Radiat Isotopes (2011) 69:1717-20. doi: 10.1016/j.apradiso.2011.02.037

110. Trani D, Reniers B, Persoon L, Podestra M, Nalbantov G, Leijenaar RT, et al. What level of accuracy is achievable for preclinical dose painting studies on a clinical irradiation platform? Radiat Res. (2015) 183:501-10. doi: $10.1667 / \mathrm{RR} 13933.1$

111. Bolcaen J, Descamps B, Boterberg T, Vanhove C, Goethals I. PET and MRI guided irradiation of a glioblastoma rat model using a microirradiator. $J$ Visual Exp.(2017) 130:1-10. doi: 10.3791/56601

Conflict of Interest Statement: The authors declare that the research was conducted in the absence of any commercial or financial relationships that could be construed as a potential conflict of interest.

Copyright (c) 2019 Donche, Verhoeven, Descamps, Bolcaen, Deblaere, Boterberg, Van den Broecke, Vanhove and Goethals. This is an open-access article distributed under the terms of the Creative Commons Attribution License (CC BY). The use, distribution or reproduction in other forums is permitted, provided the original author(s) and the copyright owner(s) are credited and that the original publication in this journal is cited, in accordance with accepted academic practice. No use, distribution or reproduction is permitted which does not comply with these terms. 